\title{
Comparação de técnicas para restauração da vegetação lenhosa de Cerrado em pastagens abandonadas ${ }^{1}$
}

\author{
Mário Guilherme de Biagi Cava ${ }^{2,6}$, Ingo Isernhagen ${ }^{3}$, Augusto Hashimoto de Mendonça ${ }^{4}$ e Giselda Durigan ${ }^{5}$
}

Recebido: 10.03.2016; aceito: 9.05.2016

\begin{abstract}
Comparing techniques to restore the woody Cerrado vegetation in abandoned pastures). Cerrado restoration has been a challenge for science and practice, which depends on experimentation. We compared the ecological efficacy and costs of direct seeding in rows, broadcast seeding, planting nursery-raised seedlings, and assisted natural or passive regeneration, to restore the Cerrado vegetation in old pastures at Canarana, MT. After 22 months, we recorded 112 woody species in the entire experimental area, from which only 16 were planted, demonstrating the high resilience of Cerrado vegetation in abandoned pastures. Richness did not differ among treatments, but direct seeding resulted in high dominance of a single species and low diversity. On the other hand, direct seeding in rows provided higher woody plant density than the other treatments. The higher costs of planting seedlings did not result in either higher richness or density. Resilience, costs and the restoration goal (recovery, commercial exploitation, or biodiversity) lead to different decisions among restoration techniques for Cerrado vegetation.
\end{abstract}

Keywords: direct seeding, natural regeneration, resilience, restoration costs, savanna

RESUMO - (Comparação de técnicas para restauração da vegetação lenhosa de Cerrado em pastagens abandonadas). Restaurar o Cerrado é um desafio para a ciência e a prática, que depende de experimentação. Comparamos, pela eficácia ecológica e custos, a semeadura direta em linhas ou a lanço, plantio de mudas e regeneração natural assistida ou passiva, para restaurar a vegetação de Cerrado em pastos abandonados em Canarana, MT. Após 22 meses, registramos 112 espécies lenhosas na área experimental como um todo, 16 das quais foram plantadas, evidenciando alta resiliência do Cerrado em pastos abandonados. A riqueza não diferiu entre tratamentos, mas a semeadura direta resultou em alta dominância de uma única espécie e baixa diversidade. Por outro lado, a semeadura direta em linhas proporcionou densidade superior aos outros tratamentos. O plantio de mudas, que apresentou custos mais elevados, não resultou em densidade ou riqueza superiores aos outros tratamentos. Resiliência, custos e metas (recobertura, exploração econômica ou biodiversidade) conduzem a diferentes decisões entre técnicas para a restauração do Cerrado.

Palavras-chave: custos da restauração, regeneração natural, resiliência, savana, semeadura direta

\section{Introdução}

Ademanda global pela restauração de ecossistemas aumentou significativamente nos últimos anos, devido à integração da restauração ecológica às principais políticas internacionais relacionadas à biodiversidade (Aronson \& Alexander 2013, Menz et al. 2013, Jørgensen 2015). Diante desta demanda, inúmeros esforços têm sido destinados à restauração. Contudo, ações relacionadas à conservação e restauração, tradicionalmente, têm sido direcionadas a florestas tropicais (Overbeck et al. 2013, Palma \& Laurance 2015). Só muito recentemente a necessidade de conservação e valorização dos campos e savanas tropicais no mundo vem ganhando espaço na literatura internacional (Bond \& Parr 2010, Lehmann 2010,

1. Parte da Dissertação de Mestrado do primeiro Autor

2. Universidade Estadual Paulista Júlio de Mesquita Filho, Rua José Barbosa de Barros, 1780, 18610-307 Botucatu, São Paulo, Brasil

3. Embrapa Agrossilvipastoril, Rodovia dos Pioneiros MT-222, km 2,5, zona rural, Caixa Postal 343, 78550-970 Sinop, Mato Grosso, Brasil

4. Universidade de São Paulo, Escola de Engenharia de São Carlos, Avenida dos Trabalhadores São-carlense, 400, 13566-590 São Carlos, São Paulo, Brasil

5. Instituto Florestal, Floresta Estadual de Assis, Caixa Postal 104, 19802-970 Assis, São Paulo, Brasil

6. Autor para correspondência: mario-cava@hotmail.com 
Parr et al. 2014, Veldman et al. 2015a, Veldman et al. 2015b, Veldman et al. 2015c). Estes ecossistemas cobrem aproximadamente $20 \%$ da superfície terrestre e, hoje, cerca de um quinto da população mundial é sustentada pelos seus serviços ecossistêmicos (Scholes \& Archer 1997). Ademais, em comparação com as florestas, os campos e savanas vêm sofrendo maior redução em extensão em decorrência de atividades humanas em regiões tropicais (Hoekstra et al. 2005).

Alinhado com os esforços globais recentes para conservação das savanas tropicais, o Brasil, por meio da Lei $\mathrm{n}^{\mathrm{o}} 12.651$ (Presidência da República 2012), que impõe a conservação ou restauração da vegetação nativa pré-existente em parte da área de todas as propriedades rurais, passou a ter significativa demanda de restauração do Cerrado, além da demanda já existente para restauração florestal. A área total a ser restaurada no país para implementação desta lei é de aproximadamente 21 Mha, dos quais 16,3 Mha ou $78 \%$ abrangem Reservas Legais (RLs) (SoaresFilho et al. 2014). Destes 16,3 Mha, cerca de 3,7 Mha referem-se ao Cerrado (Soares-Filho et al. 2014). Considerando que, em sua grande maioria, as áreas de Cerrado já convertidas foram utilizadas como pastagens (Sano et al. 2010), restabelecer a vegetação nativa após este uso da terra é o principal desafio, em extensão, para a restauração do Cerrado.

A definição de qual técnica adotar para a restauração da vegetação do Cerrado em pastagens ocupadas por gramíneas exóticas é um desafio, especialmente pela escassez de estudos científicos que fundamentem a aplicação de cada técnica em diferentes contextos. Na prática, a restauração do Cerrado tem sido conduzida sem embasamento científico, fato que muitas vezes pode resultar no insucesso da restauração ou em desperdício de recursos, em situações nas quais a resiliência do ecossistema é elevada e a restauração passiva (regeneração natural) pode ser tão eficaz para recuperação do sistema quanto técnicas de restauração ativa.

Ainda que técnicas de regeneração natural assistida sejam indicadas para restauração do Cerrado quando existir elevada resiliência (Durigan et al. 2011), essas técnicas não têm sido devidamente testadas e validadas (exemplo em Durigan et al. 1998). Em locais onde a resiliência do ecossistema é baixa, técnicas envolvendo o plantio de mudas têm sido utilizadas (Melo et al. 2004b). Todavia, a restauração da vegetação de Cerrado por plantio de mudas enfrenta diversos obstáculos. O primeiro deles é a limitação no que diz respeito à produção de mudas de espécies de Cerrado em viveiros (Lima et al. 2014), que tem resultado em plantio de espécies que não ocorrem naturalmente no Cerrado ou mesmo de espécies exóticas (Santilli \& Durigan 2014). Em segundo lugar, o crescimento lento apresentado pelas espécies em campo encarece a restauração, especialmente por tornar indispensável o controle de gramíneas exóticas por um longo período, até que as mudas plantadas possam se estabelecer e se desenvolver efetivamente (Silveira et al. 2013). Em anos recentes, outra técnica que tem sido indicada para restauração em áreas com baixa regeneração natural é a semeadura direta de espécies lenhosas. Porém, os raros estudos já desenvolvidos sobre o assunto (Pereira et al. 2013a, Pereira et al. 2013b, Silva et al. 2015) não elucidam todas as questões pendentes sobre o tema, de modo que novos estudos são necessários.

Nosso objetivo neste estudo foi comparar os resultados ecológicos e os custos de diferentes técnicas de restauração utilizando como indicadores ecológicos a riqueza de espécies e a densidade da comunidade lenhosa do Cerrado. As técnicas analisadas foram semeadura direta mecanizada em linhas (SLI), semeadura direta mecanizada a lanço (SL), plantio de mudas (PM), regeneração natural assistida (RNA, controle de gramíneas invasoras com herbicida) e restauração passiva ( $\mathrm{RP}$, controle), que têm sido sugeridas pela comunidade científica e aplicadas na prática para a restauração da vegetação de Cerrado. A semeadura direta mecanizada tem sido utilizada para a restauração em larga escala na região do Alto Xingu, para recuperação de florestas ripárias (Durigan et al. 2013) e do Cerrado (Campos-Filho et al. 2013), além de outras experiências não registradas na literatura. O PM tem sido a técnica mais amplamente utilizada (Bertoni 1992, Durigan et al. 2004, Melo et al. 2004a, Melo et al. 2004b, Felfili et al. 2005, Silva \& Côrrea 2008, Venturoli et al. 2013) e, no entanto, nem sempre bem sucedida (Santilli \& Durigan 2014). Buscamos responder, com este estudo, à seguinte questão: Qual técnica de restauração é mais eficaz na recuperação da riqueza e densidade da comunidade lenhosa do Cerrado? Esperávamos que as técnicas de PM, SLI e SL, em que são introduzidas novas espécies além das que podem colonizar a área a ser restaurada espontaneamente, fossem mais eficazes para a recuperação da riqueza do que as técnicas de RNA e RP, baseadas apenas na regeneração natural. Ademais, presumíamos que as técnicas envolvendo a semeadura direta (SLI, SL) fossem mais eficazes do que as demais técnicas para recuperação da densidade, 
uma vez que as técnicas de semeadura envolvem a deposição de alta densidade de sementes.

\section{Material e métodos}

Área de estudo - Realizamos o estudo na Fazenda Angaiá $\left(13^{\circ} 38^{\prime} 15.09^{\prime \prime} \mathrm{S}, 52^{\circ} 29^{\prime} 1.00^{\prime \prime} \mathrm{W}\right.$, altitude $430 \mathrm{~m}$ ), propriedade particular localizada a $40 \mathrm{~km}$ de Canarana, MT, Brasil. A paisagem da região é caracterizada por um mosaico formado por áreas agrícolas, pastagens e fragmentos de Cerrado e floresta. A área da propriedade, originalmente ocupada por vegetação de Cerradão (Savana Florestada, segundo IBGE 2012) foi parcialmente desmatada na década de 1980, com uso de correntão, seguido de destoca. Após o desmatamento, a terra foi destinada ao cultivo de arroz de sequeiro por uma safra e, em seguida, implantou-se pastagem com as gramíneas exóticas Urochloa humidicola (Rendle) Morrone \& Zuloaga e Andropogon gayanus Kunth. A pastagem foi abandonada alguns anos antes da implantação deste experimento. Em 2010, a vegetação lenhosa em regeneração na pastagem foi eliminada com uso de trator de esteira seguido de aração e gradagem, visando à conversão da pastagem abandonada em área agrícola para cultivo de soja. Parte dessa área foi destinada à implantação deste experimento, em novembro de 2011. A precipitação média anual na região é de $1.813 \mathrm{~mm}$, com estação seca acentuada de maio a setembro (Souza et al. 2013). A temperatura média anual é de $25^{\circ} \mathrm{C}$, pouco variando ao longo do ano, sendo $23{ }^{\circ} \mathrm{C}$ a média de temperatura em junho e $27^{\circ} \mathrm{C}$ em setembro (Souza et al. 2013). A classe de solo predominante na região é Latossolo Vermelho Amarelo (Kunz et al. 2009).

Delineamento experimental - O delineamento experimental foi em blocos casualisados, com cinco tratamentos (técnicas de restauração) e quatro repetições, em parcelas com área mínima de $2.400 \mathrm{~m}^{2}$ $(30 \mathrm{~m} \times 80 \mathrm{~m})$. As cinco técnicas de restauração que foram objeto deste estudo são descritas a seguir.

Semeadura a lanço (SL): sementes de 17 espécies lenhosas e três espécies de adubos verdes (Cajanus cajan (L.) Huth, Canavalia ensiformis (L.) DC. e Crotalaria spectabilis Röth foram semeadas a lanço por uma semeadora-adubadora, em densidades descritas na tabela 1 . O critério para seleção das espécies utilizadas baseou-se no desempenho das espécies em plantios de restauração por semeadura direta previamente efetuados pelo Instituto Socioambiental (ISA) na região do Alto Xingu, com destaque para as que tivessem potencial de exploração econômica, visando à possível restauração de reservas legais. As sementes da espécie Caryocar sp. não se adequam à semeadura mecanizada, pelas suas características morfológicas e, por isso, foram semeadas e enterradas manualmente, simultaneamente ao plantio mecanizado. As sementes de Magonia pubescens A.St.-Hil. apresentam formação de mucilagem em seu exterior após as primeiras chuvas, o que facilita sua germinação (observação em campo). Para possibilitar este processo de embebição, as sementes de $M$. pubescens também foram semeadas manualmente, de forma a garantir sua deposição sobre o solo (e não enterrando-as), de modo que durante as chuvas pudessem absorver a água com facilidade e germinar. O maquinário utilizado possui capacidade para $300 \mathrm{~L}$, fundo dosador regulável, faixa de distribuição uniforme de 7 a $16 \mathrm{~m}$ e sistema monodisco de distribuição. A semeadora foi tracionada por um trator Ford 4.630 com potência de $64 \mathrm{cv}$, com velocidade de deslocamento de $6,0 \mathrm{~km} \mathrm{~h}^{-1}$. $\mathrm{O}$ fundo dosador foi regulado de acordo com a dimensão das sementes de Hymenaea stigonocarpa Mart. ex Hayne (maior semente dentre as semeadas de forma mecanizada). As sementes das espécies lenhosas foram adquiridas da Rede de Sementes do Xingu, enquanto as sementes de adubos verdes foram adquiridas de empresas comercializadoras de sementes. A densidade de semeadura das espécies lenhosas e de adubos verdes foi determinada com base em recomendações do ISA para plantios de restauração por semeadura direta efetuados na região (Durigan et al. 2013, Campos-Filho et al. 2013). As espécies Enterolobium contortisiliquum (Vell.) Morong, H. stigonocarpa e Tachigali vulgaris L.G. Silva \& H.C. Lima foram submetidas à quebra de dormência, sendo colocadas em água a $70^{\circ} \mathrm{C}$ durante cinco minutos, antes da semeadura. As sementes das 17 espécies a serem plantadas apresentavam formas, dimensões e pesos diferentes. Para homogeneizar a semeadura, as sementes foram misturadas com areia em razão volumétrica de 2:1 (sementes: areia). Um mês antes da instalação do experimento, foi aplicado herbicida glifosato $\left(3 \mathrm{~L} \mathrm{ha}^{-1}\right)$ em todas as parcelas, para controle das gramíneas exóticas. Alguns dias antes do plantio, foi realizado o preparo convencional do solo (aração e gradagem). Após a semeadura, foi feita nova gradagem, leve e superficial, para o recobrimento das sementes. Não houve manejo pós-plantio. $\mathrm{O}$ custo estimado para implantação dessa técnica foi de $\mathrm{R} \$ 1.900,00 \mathrm{ha}^{-1}$. 
Semeadura em linhas (SLI): foram semeadas as mesmas espécies utilizadas na $\mathrm{SL}$, nas mesmas densidades (tabela 1) e submetidas aos mesmos tratamentos de quebra de dormência. O preparo de solo foi o mesmo da SL. O implemento utilizado foi uma plantadora agrícola convencional com 13 linhas, regulada com espaçamento de $45 \mathrm{~cm}$ entre as linhas e armazenando conjuntos de sementes distintos nas caixas de sementes e adubos da plantadora. A mistura armazenada na caixa de sementes compreendeu as sementes de Mabea fistulifera Mart. e C. cajan (adubo verde). Já a mistura armazenada na caixa de adubos incluiu as sementes das outras 14 espécies lenhosas e das espécies de adubos verdes C. ensiformis e C. spectabilis. A plantadora foi tracionada por um trator John Deere $6.145 \mathrm{~J}$ com potência de $145 \mathrm{cv}$, com velocidade de deslocamento de $6,0 \mathrm{~km} \mathrm{~h}^{-1}$. Para evitar entupimento devido ao tamanho das sementes,

Tabela 1. Espécies vegetais introduzidas por sementes pelas técnicas de semeadura a lanço (SL) e semeadura em linhas (SLI) ou plantio de mudas (PM) em cada parcela de $2.400 \mathrm{~m}^{2}$ em experimento de restauração de Cerrado em Canarana, MT, Brasil.

Table 1. Plant species introduced by seeds through broadcast seeding (SL) and seeding in rows (SLI) or planting nurseryraised tree seedlings (PM) in each plot $\left(2,400 \mathrm{~m}^{2}\right)$ in a Cerrado restoration experiment, Canarana, Mato Grosso State, Brazil.

\begin{tabular}{|c|c|c|}
\hline Espécies & $\begin{array}{c}\text { Sementes/parcela } \\
\text { (SLI, SL) }\end{array}$ & $\begin{array}{c}\text { Mudas/parcela } \\
\text { (PM) }\end{array}$ \\
\hline Anacardium nanum A. St.-Hil. ${ }^{5}$ & 240 & 13 \\
\hline Anadenanthera colubrina var. cebil (Griseb.) Altschul ${ }^{5}$ & 240 & 6 \\
\hline Apuleia leiocarpa (Vogel) J.F. Macbr. ${ }^{5}$ & 27 & 7 \\
\hline Astronium fraxinifolium $\mathrm{Schott}^{4}$ & 3.360 & 7 \\
\hline Cajanus cajan (L.) Huth ${ }^{1}$ & 2.400 & 0 \\
\hline Canavalia ensiformis (L.) DC. ${ }^{1}$ & 6.000 & 0 \\
\hline Caryocar sp. ${ }^{2}$ & 80 & 13 \\
\hline Copaifera langsdorffii Desf. ${ }^{4}$ & 80 & 7 \\
\hline Crotalaria spectabilis Röth. ${ }^{1}$ & 14.400 & 0 \\
\hline Dipteryx alata Vogel $^{4}$ & 400 & 13 \\
\hline Enterolobium contortisiliquum (Vell.) Morong ${ }^{5}$ & 1.600 & 33 \\
\hline Guazuma ulmifolia Lam. ${ }^{5}$ & 24.000 & 25 \\
\hline Handroanthus impetiginosus (Mart. ex DC.) Mattos ${ }^{5}$ & 960 & 6 \\
\hline Hymenaea stigonocarpa Mart. ex Hayne ${ }^{4}$ & 80 & 6 \\
\hline Mabea fistulifera Mart. $^{4}$ & 16.000 & 35 \\
\hline Magonia pubescens A. St.-Hil. ${ }^{4}$ & 686 & 6 \\
\hline Myracrodruon urundeuva Allemão ${ }^{5}$ & 2.400 & 7 \\
\hline Senna velutina (Vogel) H.S. Irwin \& Barneby ${ }^{3,5}$ & 720 & 0 \\
\hline Sterculia apetala (Jacq.) H.Karst. ${ }^{5}$ & 144 & 13 \\
\hline Tachigali vulgaris L.G. Silva \& H.C. Lima ${ }^{4}$ & 360 & 8 \\
\hline Total & 74.176 & 205 \\
\hline
\end{tabular}

${ }^{1}$ Espécies de adubos verdes utilizadas nos tratamentos relacionados à semeadura direta.

${ }^{2} \mathrm{~A}$ identificação botânica do chamado pequi dos índios do Xingu ainda é controversa e, por isso, a espécie é apresentada em nível de gênero. Trata-se de uma árvore de porte superior ao de Caryocar brasiliense Cambess, com frutos maiores e maior quantidade de polpa em relação à usualmente encontrada na espécie em ambientes naturais.

${ }^{3}$ Espécie lenhosa utilizada somente nos tratamentos relacionados à semeadura direta.

${ }^{4}$ Espécies pertencentes à flora regional, levando em consideração a amostragem efetuada por Kunz et al. (2009) em um trecho de Cerradão no município de Canarana, MT, Brasil.

${ }^{5}$ Espécies que pertencem à flora do Cerrado, de acordo com Sano et al. (2008), mas que não foram amostradas por Kunz et al. (2009) na região de estudo. 
principalmente pelas sementes de $H$. stigonocarpa, que possuem as maiores dimensões entre as espécies semeadas de forma mecanizada, substituímos a botinha, que se encaixa à mangueira flexível e conduz as sementes da caixa de adubos para o disco de plantio, por um tubo de PVC compatível. As misturas de sementes foram pesadas para regulagem da plantadora, de modo que as saídas da caixa de sementes e da caixa de adubos estivessem de acordo com a tabela fornecida pelo fabricante para a densidade planejada de sementes por hectare. A semeadura foi efetuada de forma idêntica a um plantio agrícola. Assim como no tratamento anterior, as sementes de Caryocar sp. e M. pubescens foram semeadas manualmente. Um ano após a semeadura, foi aplicado herbicida glifosato (3 $\mathrm{L} \mathrm{ha}^{-1}$ ) nas entrelinhas, com bomba costal, dirigido às touceiras de gramíneas exóticas. $\mathrm{O}$ custo estimado para implantação dessa técnica e manutenção nos primeiros dois anos foi de $\mathrm{R} \$ 2.100,00 \mathrm{ha}^{-1}$.

Plantio de mudas (PM): as mudas plantadas pertenciam às mesmas espécies lenhosas utilizadas nas técnicas de semeadura direta (tabela 1), exceto Senna velutina (Vogel) H.S.Irwin \& Barneby, não incluída no plantio por mudas. As mudas utilizadas foram produzidas no viveiro municipal de Canarana, a partir de sementes coletadas na região do Alto Xingu. O espaçamento foi de $4 \mathrm{~m}$ entre as linhas e $3 \mathrm{~m}$ entre plantas na linha. As mudas foram distribuídas (quantidade e posição) de acordo com taxas de crescimento e atributos funcionais das espécies. Para o controle de gramíneas invasoras, antes do plantio foram efetuadas duas aplicações de herbicida glifosato $\left(3 \mathrm{~L} \mathrm{ha}^{-1}\right)(7$ e 30 dias antes). Os sulcos de plantio (40 $\mathrm{cm}$ de profundidade) foram abertos mecanicamente, com um sulcador de uma linha tracionado por um trator. Após sulcagem, foi aplicado, somente nas linhas de plantio, o herbicida pré-emergente sulfentrazone, na dosagem de $1 \mathrm{~L} \mathrm{ha}^{-1}$. O controle das gramíneas exóticas durante o primeiro ano após o plantio foi intensivo, por meio de roçagem tratorizada frequente e cinco aplicações de herbicida glifosato. $\mathrm{O}$ custo estimado para esta técnica e manutenção nos primeiros dois anos foi de $\mathrm{R} \$ 3.300,00 \mathrm{ha}^{-1}$.

Regeneração natural assistida (RNA): esta técnica envolveu somente o controle das gramíneas exóticas, por meio da aplicação de herbicida glifosato $\left(3 \mathrm{~L} \mathrm{ha}^{-1}\right)$. $\mathrm{O}$ produto foi aplicado via pulverizador autopropelido 4.730 John Deere, com barra de aplicação de $30 \mathrm{~m}$, um mês antes e um ano após a implantação do experimento. $O$ custo estimado para implantação dessa técnica e manutenção nos primeiros dois anos foi de $\mathrm{R} \$ 200,00 \mathrm{ha}^{-1}$.

Restauração passiva (RP, controle): neste tratamento não foi realizado nenhum tipo de intervenção ao longo de todo o período de monitoramento do experimento, de modo a representar o potencial de regeneração natural da vegetação, caso nenhuma ação de restauração fosse realizada. A técnica, portanto, não apresentou custos.

Amostragem da vegetação - Para amostragem da comunidade lenhosa (árvores e arbustos), dentro de cada parcela $(30 \times 80 \mathrm{~m})$, demarcamos três subparcelas permanentes de $20 \mathrm{~m}^{2}(20 \mathrm{~m} \times 1 \mathrm{~m})$. As subparcelas foram dispostas em sentido diagonal em relação à borda das parcelas. Para análise dos dados, as três subparcelas foram tratadas conjuntamente, ou seja, a área amostral considerada nas análises foi de $60 \mathrm{~m}^{2}$. Assim, para cada tratamento foram amostrados 240 $\mathrm{m}^{2}$. Aos 22 meses, contabilizamos e identificamos todos os indivíduos lenhosos com altura mínima de $50 \mathrm{~cm}$, plantados e/ou oriundos de regeneração natural dentro das parcelas amostrais (doravante denominados regenerantes). Os espécimes foram identificados em campo sempre que possível. Nos demais casos, coletamos material botânico para identificação posterior com base na literatura ou consulta a especialistas. Diante da dificuldade em identificar plantas jovens, muitos táxons foram mantidos em nível de gênero ou como morfoespécies. A nomenclatura das espécies seguiu a Flora do Brasil (Flora do Brasil 2020, em construção).

Análise de dados - Para avaliar a eficácia ecológica das técnicas de restauração, calculamos a riqueza específica média (número de espécies amostradas dentro da área de $60 \mathrm{~m}^{2}$ ) e a densidade média (indivíduos $\mathrm{ha}^{-1}$ ), utilizando estas variáveis como indicadores ecológicos de sucesso da restauração (Ruiz-Jaen \& Aide 2005).

Para detectar diferenças na eficácia da restauração entre as técnicas, submetemos as variáveis densidade e riqueza das comunidades à Análise de Variância (ANOVA), após verificar o atendimento dos pressupostos. Em seguida, aplicamos o teste Tukey $(\mathrm{p} \leq 0,05)$.

Posteriormente, elaboramos curvas de rarefação baseadas no número de indivíduos e comparamos os tratamentos pela riqueza rarefeita (Magurran 2004), que é considerada uma boa representação da diversidade das comunidades (Durigan 2009). 
Para esta análise, utilizamos o número mínimo de 48 indivíduos por tratamento, que foi o número de espécies registrado no tratamento de plantio de mudas.

\section{Resultados}

Aos 22 meses registramos, em toda a área amostral $\left(1.200 \mathrm{~m}^{2}\right), 1.787$ indivíduos (14.892 indivíduos ha $\left.{ }^{-1}\right)$, pertencentes a 112 espécies lenhosas (tabela 2). Entre as espécies amostradas, 16 foram introduzidas por sementes ou mudas e 96 colonizaram a área a partir de mecanismos de regeneração natural (rebrota ou chuva de sementes). Dentre as espécies introduzidas, Apuleia leiocarpa (Vogel) J.F.Macbr. foi a única não registrada durante a amostragem, uma vez que não se estabeleceu nem por sementes e nem por mudas. Entre as espécies introduzidas nos tratamentos de semeadura, dezesseis apresentaram densidade relativa na comunidade inferior a 3\%, enquanto $M$. fistulifera apresentou-se nesses tratamentos com densidade relativa superior a $80 \%$ dos indivíduos (tabela 2). Assim, mesmo nesses tratamentos, a composição da comunidade foi determinada pela regeneração natural, que correspondeu a $72 \%$ das espécies na semeadura em linhas e $60 \%$ das espécies na semeadura a lanço. No tratamento por plantio de mudas não se observou dominância tão evidente, sendo a maior densidade relativa apresentada por Guazuma ulmifolia Lam., com $21 \%$ dos indivíduos amostrados e menos da metade das espécies (46\%) foram oriundas de regeneração natural.

As comunidades resultantes das diferentes técnicas testadas não apresentaram diferença significativa em relação à riqueza específica por parcela $(\mathrm{F}=1,711, \mathrm{p}>0,05$; figura 1$)$. Contudo, as comunidades originadas pelas técnicas de restauração apresentaram diferença significativa em relação à densidade $(\mathrm{F}=11,731, \mathrm{p}<0,05$; figura 1$)$. A técnica SLI resultou em comunidade com densidade superior às comunidades resultantes das técnicas RP, RNA e $\mathrm{PM}$, não diferindo estatisticamente da comunidade resultante da técnica SL, a qual, por sua vez, não diferiu de nenhuma das comunidades resultantes das outras técnicas.

A riqueza rarefeita para 48 indivíduos foi semelhante entre os tratamentos RP (25 espécies), RNA (24 espécies) e PM (26 espécies), com valores superiores em comparação com as comunidades resultantes dos tratamentos SLI (6 espécies) e SL (8 espécies), que não diferiram entre si (figura 2).

\section{Discussão}

As técnicas de restauração ativa não diferiram das técnicas baseadas na regeneração natural no que diz respeito à recuperação da riqueza da comunidade, contrariando a expectativa de que a introdução das espécies por sementes ou mudas resultaria em riqueza da comunidade mais elevada. A regeneração natural mostrou-se, portanto, tão eficaz quanto as técnicas de restauração ativa na recuperação da riqueza. O grande número de espécies que surgiram espontaneamente evidenciou que a área de estudo apresentava elevada resiliência. Os indivíduos regenerantes podem ter sido originados pela chuva de sementes, pelo banco de sementes ou pela rebrota de estruturas subterrâneas (raízes, xilopódios, tubérculos etc.). Neste estudo não quantificamos as estratégias de regeneração dos indivíduos amostrados, mas observamos, em campo, a predominância de rebrota. De fato, estudos anteriores sugerem que as espécies lenhosas de Cerrado apresentam forte limitação para se estabelecerem por sementes (Salazar et al. 2012) e que a principal estratégia de regeneração dessas espécies em áreas submetidas a distúrbios é a rebrota de estruturas vegetativas pré-existentes (Barros 1966, Brando \& Durigan 2004, Hoffmann 1998, Medeiros \& Miranda 2008, Salazar \& Goldstein 2014). A vegetação lenhosa do Cerrado apresenta elevada capacidade de rebrota em comparação com outros tipos de vegetação (Durigan 2003). Estudos têm demonstrado que áreas de Cerrado convertidas em pastagens (Durigan et al. 1998) e silvicultura (Abreu et al. 2011, Neri et al. 2005, Saporetti Júnior et al. 2003) podem manter elevada capacidade de regeneração natural por muitos anos. Durigan et al. (1997), ao avaliarem o potencial de regeneração natural em área de Cerrado após 22 anos de cultivo de Eucalyptus citriodora, verificaram que dois anos após o corte raso da floresta de eucaliptos e abandono da área, a comunidade resultante da regeneração natural apresentou densidade e número de espécies semelhantes a um remanescente de Cerradão conservado, utilizado como referência. Neste sentido, os autores indicaram que a simples eliminação da espécie florestal cultivada poderia resultar em rápida regeneração da vegetação lenhosa do Cerrado. Desta forma, a elevada resiliência do Cerrado pode explicar o sucesso da regeneração natural na área de estudo, considerando-se que a área foi cultivada e depois utilizada como pastagem por cerca de 30 anos após o desmatamento. 
Tabela 2. Espécies lenhosas amostradas na área de estudo, Canarana, MT, Brasil, com dados de abundância em cada tratamento (técnica de restauração): densidade absoluta (DA), que expressa o número de indivíduos por hectare e densidade relativa (DR), que expressa a porcentagem de indivíduos da espécie em relação ao total de indivíduos amostrados no tratamento. Os tratamentos foram: restauração passiva (RP), regeneração natural assistida (RNA), semeadura em linhas (SLI), semeadura a lanço (SL) e plantio de mudas (PM). (*) Espécies introduzidas por sementes ou mudas.

Table 2.Woody species sampled in the study area, Canarana, Mato Grosso State, Brazil, with abundance data for each treatment (restoration technique): absolute density (DA), which expresses the number of individuals per hectare and relative density (DR), which expresses the percentage of individuals of a species among all individuals sampled in each treatment. The treatments were: passive restoration (RP), assisted natural regeneration (RNA), seeding in rows (SLI), broadcast seeding $(\mathrm{SL})$, and planting nursery-raised tree seedlings $(\mathrm{PM}) .\left({ }^{*}\right)$ species introduced by seeds or seedlings.

\begin{tabular}{|c|c|c|c|c|c|c|c|c|c|c|}
\hline \multirow[t]{2}{*}{ Espécies } & \multicolumn{2}{|c|}{$\mathrm{RP}$} & \multicolumn{2}{|c|}{ RNA } & \multicolumn{2}{|c|}{ SLI } & \multicolumn{2}{|c|}{ SL } & \multicolumn{2}{|c|}{ PM } \\
\hline & DA & DR & DA & DR & DA & DR & DA & DR & DA & DR \\
\hline Anacardium nanum A.St.-Hil.* & 0 & 0,0 & 0 & 0,0 & 83 & 0,2 & 167 & 0,8 & 125 & 6,3 \\
\hline $\begin{array}{l}\text { Anadenanthera colubrina var. cebil } \\
\text { (Griseb.) Altschul* }\end{array}$ & 0 & 0,0 & 0 & 0,0 & 42 & 0,1 & 458 & 2,3 & 125 & 6,3 \\
\hline Andira sp. & 208 & 2,0 & 0 & 0,0 & 83 & 0,2 & 0 & 0,0 & 0 & 0,0 \\
\hline Annona coriacea Mart. & 83 & 0,8 & 167 & 2,7 & 125 & 0,4 & 125 & 0,6 & 42 & 2,1 \\
\hline Annona sp. & 0 & 0,0 & 0 & 0,0 & 42 & 0,1 & 0 & 0,0 & 0 & 0,0 \\
\hline Aspidosperma multiflorum A. DC. & 42 & 0,4 & 0 & 0,0 & 0 & 0,0 & 0 & 0,0 & 0 & 0,0 \\
\hline Aspidosperma nobile Müll.Arg. & 42 & 0,4 & 0 & 0,0 & 0 & 0,0 & 0 & 0,0 & 0 & 0,0 \\
\hline Aspidosperma sp. & 83 & 0,8 & 0 & 0,0 & 0 & 0,0 & 0 & 0,0 & 0 & 0,0 \\
\hline Aspidosperma subincanum Mart. & 83 & 0,8 & 0 & 0,0 & 0 & 0,0 & 0 & 0,0 & 0 & 0,0 \\
\hline Aspidosperma tomentosum Mart. & 42 & 0,4 & 0 & 0,0 & 0 & 0,0 & 0 & 0,0 & 0 & 0,0 \\
\hline Astronium fraxinifolium Schott* & 333 & 3,1 & 0 & 0,0 & 83 & 0,2 & 42 & 0,2 & 125 & 6,3 \\
\hline Banisteriopsis sp. & 0 & 0,0 & 417 & 6,7 & 0 & 0,0 & 0 & 0,0 & 0 & 0,0 \\
\hline Bauhinia sp. & 417 & 3,9 & 42 & 0,7 & 1.042 & 2,9 & 292 & 1,5 & 83 & 4,2 \\
\hline Bowdichia virgilioides Kunth & 42 & 0,4 & 0 & 0,0 & 0 & 0,0 & 0 & 0,0 & 0 & 0,0 \\
\hline Brosimum gaudichaudii Trécul & 333 & 3,1 & 167 & 2,7 & 333 & 0,9 & 125 & 0,6 & 42 & 2,1 \\
\hline Byrsonima pachyphylla A. Juss. & 0 & 0,0 & 42 & 0,7 & 0 & 0,0 & 0 & 0,0 & 0 & 0,0 \\
\hline Byrsonima sp. 1 & 0 & 0,0 & 0 & 0,0 & 167 & 0,5 & 0 & 0,0 & 42 & 2,1 \\
\hline Byrsonima sp. 2 & 167 & 1,6 & 333 & 5,3 & 0 & 0,0 & 0 & 0,0 & 0 & 0,0 \\
\hline Byrsonima sp. 3 & 83 & 0,8 & 125 & 2,0 & 0 & 0,0 & 0 & 0,0 & 0 & 0,0 \\
\hline Byrsonima sp. 4 & 125 & 1,2 & 42 & 0,7 & 0 & 0,0 & 0 & 0,0 & 0 & 0,0 \\
\hline Campomanesia sp. & 458 & 4,3 & 208 & 3,3 & 0 & 0,0 & 0 & 0,0 & 0 & 0,0 \\
\hline Caryocar sp.* & 0 & 0,0 & 0 & 0,0 & 83 & 0,2 & 83 & 0,4 & 42 & 2,1 \\
\hline Casearia sylvestris $\mathrm{Sw}$. & 125 & 1,2 & 0 & 0,0 & 42 & 0,1 & 0 & 0,0 & 0 & 0,0 \\
\hline $\begin{array}{l}\text { Cochlospermum regium (Mart ex Schrank) } \\
\text { Pilg. }\end{array}$ & 83 & 0,8 & 0 & 0,0 & 0 & 0,0 & 0 & 0,0 & 0 & 0,0 \\
\hline Connarus sp. & 42 & 0,4 & 0 & 0,0 & 0 & 0,0 & 0 & 0,0 & 0 & 0,0 \\
\hline Connarus suberosus Planch. & 125 & 1,2 & 167 & 2,7 & 0 & 0,0 & 0 & 0,0 & 0 & 0,0 \\
\hline Copaifera langsdorffii Desf.* & 167 & 1,6 & 83 & 1,3 & 42 & 0,1 & 0 & 0,0 & 0 & 0,0 \\
\hline Cordiera sessilis (Vell.) Kuntze & 0 & 0,0 & 42 & 0,7 & 0 & 0,0 & 0 & 0,0 & 0 & 0,0 \\
\hline Cordiera sp. 1 & 42 & 0,4 & 0 & 0,0 & 0 & 0,0 & 0 & 0,0 & 0 & 0,0 \\
\hline
\end{tabular}


Tabela 2 (continuação)

\begin{tabular}{|c|c|c|c|c|c|c|c|c|c|c|}
\hline \multirow[t]{2}{*}{ Espécies } & \multicolumn{2}{|c|}{$\mathrm{RP}$} & \multicolumn{2}{|c|}{ RNA } & \multicolumn{2}{|c|}{ SLI } & \multicolumn{2}{|c|}{ SL } & \multicolumn{2}{|c|}{ PM } \\
\hline & DA & DR & DA & DR & DA & DR & DA & DR & DA & DR \\
\hline Cordiera sp. 2 & 42 & 0,4 & 0 & 0,0 & 0 & 0,0 & 0 & 0,0 & 0 & 0,0 \\
\hline Curatella americana $\mathrm{L}$. & 1.083 & 10,2 & 583 & 9,3 & 250 & 0,7 & 0 & 0,0 & 42 & 2,1 \\
\hline Dalbergia sp. & 0 & 0,0 & 83 & 1,3 & 125 & 0,4 & 83 & 0,4 & 0 & 0,0 \\
\hline Davilla elliptica A. St.-Hil. & 0 & 0,0 & 42 & 0,7 & 0 & 0,0 & 0 & 0,0 & 0 & 0,0 \\
\hline Dimorphandra mollis Benth. & 0 & 0,0 & 42 & 0,7 & 0 & 0,0 & 0 & 0,0 & 0 & 0,0 \\
\hline Dioclea sp. 1 & 0 & 0,0 & 42 & 0,7 & 0 & 0,0 & 0 & 0,0 & 0 & 0,0 \\
\hline Dioclea sp. 2 & 0 & 0,0 & 42 & 0,7 & 0 & 0,0 & 0 & 0,0 & 0 & 0,0 \\
\hline Dioclea sp. 3 & 42 & 0,4 & 42 & 0,7 & 0 & 0,0 & 0 & 0,0 & 0 & 0,0 \\
\hline Dioclea sp. 4 & 83 & 0,8 & 0 & 0,0 & 0 & 0,0 & 0 & 0,0 & 0 & 0,0 \\
\hline Diospyros hispida A. DC. & 42 & 0,4 & 0 & 0,0 & 0 & 0,0 & 0 & 0,0 & 0 & 0,0 \\
\hline Dipteryx alata Vogel* & 83 & 0,8 & 208 & 3,3 & 0 & 0,0 & 542 & 2,7 & 42 & 2,1 \\
\hline $\begin{array}{l}\text { Enterolobium contortisiliquum (Vell.) } \\
\text { Morong* }\end{array}$ & 0 & 0,0 & 0 & 0,0 & 0 & 0,0 & 167 & 0,8 & 42 & 2,1 \\
\hline Eremanthus sp. & 42 & 0,4 & 42 & 0,7 & 0 & 0,0 & 0 & 0,0 & 0 & 0,0 \\
\hline $\begin{array}{l}\text { Eriotheca gracilipes (K. Schum.) A. } \\
\text { Robyns }\end{array}$ & 0 & 0,0 & 0 & 0,0 & 167 & 0,5 & 0 & 0,0 & 0 & 0,0 \\
\hline Erythroxylum sp. & 0 & 0,0 & 42 & 0,7 & 0 & 0,0 & 0 & 0,0 & 0 & 0,0 \\
\hline Eugenia dysenterica (Mart.) DC. & 42 & 0,4 & 0 & 0,0 & 0 & 0,0 & 0 & 0,0 & 0 & 0,0 \\
\hline Fabaceae 1 & 0 & 0,0 & 42 & 0,7 & 0 & 0,0 & 0 & 0,0 & 0 & 0,0 \\
\hline $\begin{array}{l}\text { Guapira graciliflora (Mart. ex Schmidt) } \\
\text { Lundell }\end{array}$ & 208 & 2,0 & 125 & 2,0 & 208 & 0,6 & 125 & 0,6 & 0 & 0,0 \\
\hline Guazuma ulmifolia Lam.* & 0 & 0,0 & 0 & 0,0 & 83 & 0,2 & 83 & 0,4 & 417 & 20,8 \\
\hline Guettarda viburnoides Cham. \& Schltdl. & 42 & 0,4 & 0 & 0,0 & 0 & 0,0 & 0 & 0,0 & 0 & 0,0 \\
\hline $\begin{array}{l}\text { Handroanthus impetiginosus (Mart. ex } \\
\text { DC.) Mattos* }\end{array}$ & 0 & 0,0 & 0 & 0,0 & 0 & 0,0 & 0 & 0,0 & 42 & 2,1 \\
\hline Handroanthus ochraceus (Cham.) Mattos. & 42 & 0,4 & 0 & 0,0 & 0 & 0,0 & 0 & 0,0 & 42 & 2,1 \\
\hline Heteropterys byrsonimifolia A. Juss. & 0 & 0,0 & 42 & 0,7 & 0 & 0,0 & 0 & 0,0 & 0 & 0,0 \\
\hline Hymenaea stigonocarpa Mart. ex Hayne* & 167 & 1,6 & 42 & 0,7 & 0 & 0,0 & 0 & 0,0 & 83 & 4,2 \\
\hline Mabea fistulifera Mart.* & 0 & 0,0 & 0 & 0,0 & 30.500 & 85,6 & 16.292 & 81,6 & 125 & 6,3 \\
\hline Machaerium sp. & 167 & 1,6 & 42 & 0,7 & 0 & 0,0 & 0 & 0,0 & 0 & 0,0 \\
\hline Magonia pubescens A.St.-Hil.* & 250 & 2,4 & 83 & 1,3 & 83 & 0,2 & 0 & 0,0 & 83 & 4,2 \\
\hline Malpighiaceae 1 & 0 & 0,0 & 42 & 0,7 & 0 & 0,0 & 0 & 0,0 & 0 & 0,0 \\
\hline Malvaceae 1 & 0 & 0,0 & 42 & 0,7 & 0 & 0,0 & 0 & 0,0 & 0 & 0,0 \\
\hline Malvaceae 2 & 83 & 0,8 & 0 & 0,0 & 0 & 0,0 & 0 & 0,0 & 0 & 0,0 \\
\hline Matayba guianensis Aubl. & 42 & 0,4 & 42 & 0,7 & 0 & 0,0 & 0 & 0,0 & 0 & 0,0 \\
\hline Morfotipo 1 & 0 & 0,0 & 0 & 0,0 & 0 & 0,0 & 42 & 0,2 & 0 & 0,0 \\
\hline Morfotipo 10 & 0 & 0,0 & 0 & 0,0 & 42 & 0,1 & 0 & 0,0 & 0 & 0,0 \\
\hline
\end{tabular}


Tabela 2 (continuação)

\begin{tabular}{|c|c|c|c|c|c|c|c|c|c|c|}
\hline \multirow[t]{2}{*}{ Espécies } & \multicolumn{2}{|c|}{$\mathrm{RP}$} & \multicolumn{2}{|c|}{ RNA } & \multicolumn{2}{|c|}{ SLI } & \multicolumn{2}{|c|}{ SL } & \multicolumn{2}{|c|}{ PM } \\
\hline & DA & DR & DA & DR & $\mathrm{DA}$ & DR & DA & DR & DA & $\mathrm{DR}$ \\
\hline Morfotipo 107 & 0 & 0,0 & 0 & 0,0 & 0 & 0,0 & 0 & 0,0 & 42 & 2,1 \\
\hline Morfotipo 108 & 0 & 0,0 & 0 & 0,0 & 0 & 0,0 & 0 & 0,0 & 42 & 2,1 \\
\hline Morfotipo 109 & 0 & 0,0 & 0 & 0,0 & 0 & 0,0 & 0 & 0,0 & 42 & 2,1 \\
\hline Morfotipo 11 & 0 & 0,0 & 0 & 0,0 & 42 & 0,1 & 0 & 0,0 & 0 & 0,0 \\
\hline Morfotipo 12 & 0 & 0,0 & 0 & 0,0 & 42 & 0,1 & 0 & 0,0 & 0 & 0,0 \\
\hline Morfotipo 13 & 0 & 0,0 & 0 & 0,0 & 42 & 0,1 & 0 & 0,0 & 0 & 0,0 \\
\hline Morfotipo 14 & 0 & 0,0 & 0 & 0,0 & 42 & 0,1 & 0 & 0,0 & 0 & 0,0 \\
\hline Morfotipo 15 & 0 & 0,0 & 0 & 0,0 & 42 & 0,1 & 0 & 0,0 & 0 & 0,0 \\
\hline Morfotipo 2 & 0 & 0,0 & 0 & 0,0 & 0 & 0,0 & 42 & 0,2 & 0 & 0,0 \\
\hline Morfotipo 3 & 0 & 0,0 & 0 & 0,0 & 0 & 0,0 & 42 & 0,2 & 0 & 0,0 \\
\hline Morfotipo 4 & 0 & 0,0 & 0 & 0,0 & 0 & 0,0 & 42 & 0,2 & 0 & 0,0 \\
\hline Morfotipo 43 & 42 & 0,4 & 0 & 0,0 & 0 & 0,0 & 0 & 0,0 & 0 & 0,0 \\
\hline Morfotipo 44 & 42 & 0,4 & 0 & 0,0 & 0 & 0,0 & 0 & 0,0 & 0 & 0,0 \\
\hline Morfotipo 45 & 83 & 0,8 & 0 & 0,0 & 0 & 0,0 & 0 & 0,0 & 0 & 0,0 \\
\hline Morfotipo 46 & 167 & 1,6 & 0 & 0,0 & 0 & 0,0 & 0 & 0,0 & 0 & 0,0 \\
\hline Morfotipo 5 & 0 & 0,0 & 0 & 0,0 & 0 & 0,0 & 42 & 0,2 & 0 & 0,0 \\
\hline Morfotipo 6 & 0 & 0,0 & 0 & 0,0 & 0 & 0,0 & 42 & 0,2 & 0 & 0,0 \\
\hline Morfotipo 7 & 0 & 0,0 & 0 & 0,0 & 42 & 0,1 & 0 & 0,0 & 0 & 0,0 \\
\hline Morfotipo 71 & 0 & 0,0 & 42 & 0,7 & 0 & 0,0 & 0 & 0,0 & 0 & 0,0 \\
\hline Morfotipo 72 & 0 & 0,0 & 42 & 0,7 & 0 & 0,0 & 0 & 0,0 & 0 & 0,0 \\
\hline Morfotipo 73 & 0 & 0,0 & 42 & 0,7 & 0 & 0,0 & 0 & 0,0 & 0 & 0,0 \\
\hline Morfotipo 74 & 0 & 0,0 & 42 & 0,7 & 0 & 0,0 & 0 & 0,0 & 0 & 0,0 \\
\hline Morfotipo 75 & 0 & 0,0 & 42 & 0,7 & 0 & 0,0 & 0 & 0,0 & 0 & 0,0 \\
\hline Morfotipo 8 & 0 & 0,0 & 0 & 0,0 & 42 & 0,1 & 0 & 0,0 & 0 & 0,0 \\
\hline Morfotipo 9 & 0 & 0,0 & 0 & 0,0 & 42 & 0,1 & 0 & 0,0 & 0 & 0,0 \\
\hline Myracrodruon urundeuva Allemão* & 0 & 0,0 & 0 & 0,0 & 42 & 0,1 & 125 & 0,6 & 42 & 2,1 \\
\hline Myrcia lanuginosa (O. Berg) Nied. & 458 & 4,3 & 292 & 4,7 & 42 & 0,1 & 0 & 0,0 & 0 & 0,0 \\
\hline Myrcia lingua (O. Berg) Mattos & 42 & 0,4 & 125 & 2,0 & 0 & 0,0 & 0 & 0,0 & 0 & 0,0 \\
\hline Myrtaceae 1 & 42 & 0,4 & 0 & 0,0 & 0 & 0,0 & 42 & 0,2 & 0 & 0,0 \\
\hline Myrtaceae 2 & 0 & 0,0 & 0 & 0,0 & 0 & 0,0 & 42 & 0,2 & 0 & 0,0 \\
\hline Myrtaceae 3 & 0 & 0,0 & 0 & 0,0 & 0 & 0,0 & 42 & 0,2 & 0 & 0,0 \\
\hline Peritassa campestris (Cambess.) A.C. Sm. & 83 & 0,8 & 0 & 0,0 & 0 & 0,0 & 0 & 0,0 & 0 & 0,0 \\
\hline Plenckia populnea Reissek & 42 & 0,4 & 0 & 0,0 & 0 & 0,0 & 0 & 0,0 & 0 & 0,0 \\
\hline Pouteria sp. & 208 & 2,0 & 83 & 1,3 & 125 & 0,4 & 0 & 0,0 & 0 & 0,0 \\
\hline Protium sp. & 83 & 0,8 & 0 & 0,0 & 0 & 0,0 & 0 & 0,0 & 0 & 0,0 \\
\hline Qualea parviflora Mart. & 42 & 0,4 & 42 & 0,7 & 83 & 0,2 & 42 & 0,2 & 0 & 0,0 \\
\hline Qualea sp. & 500 & 4,7 & 125 & 2,0 & 42 & 0,1 & 83 & 0,4 & 83 & 4,2 \\
\hline Roupala montana Aubl. & 708 & 6,7 & 625 & 10,0 & 83 & 0,2 & 42 & 0,2 & 42 & 2,1 \\
\hline Rourea induta Planch. & 42 & 0,4 & 83 & 1,3 & 0 & 0,0 & 0 & 0,0 & 0 & 0,0 \\
\hline
\end{tabular}


Tabela 2 (continuação)

\begin{tabular}{|c|c|c|c|c|c|c|c|c|c|c|}
\hline \multirow[t]{2}{*}{ Espécies } & \multicolumn{2}{|c|}{$\mathrm{RP}$} & \multicolumn{2}{|c|}{ RNA } & \multicolumn{2}{|c|}{ SLI } & \multicolumn{2}{|c|}{ SL } & \multicolumn{2}{|c|}{ PM } \\
\hline & DA & DR & DA & DR & DA & DR & DA & DR & DA & DR \\
\hline $\begin{array}{l}\text { Senna velutina (Vogel) H.S.Irwin \& } \\
\text { Barneby* }\end{array}$ & 1.542 & 14,5 & 958 & 15,3 & 958 & 2,7 & 333 & 1,7 & 42 & 2,1 \\
\hline Simarouba versicolor A.St. -Hil & 42 & 0,4 & 0 & 0,0 & 0 & 0,0 & 0 & 0,0 & 0 & 0,0 \\
\hline Sterculia apetala (Jacq.) H. Karst.* & 0 & 0,0 & 0 & 0,0 & 42 & 0,1 & 83 & 0,4 & 83 & 4,2 \\
\hline Stryphnodendron rotundifolium Mart. & 83 & 0,8 & 0 & 0,0 & 0 & 0,0 & 0 & 0,0 & 0 & 0,0 \\
\hline Stryphnodendron sp. & 0 & 0,0 & 0 & 0,0 & 83 & 0,2 & 83 & 0,4 & 42 & 2,1 \\
\hline Tachigali vulgaris L.G.Silva \& H.C.Lima* & 0 & 0,0 & 0 & 0,0 & 0 & 0,0 & 208 & 1,0 & 0 & 0,0 \\
\hline Terminalia argentea Mart. & 42 & 0,4 & 42 & 0,7 & 0 & 0,0 & 0 & 0,0 & 0 & 0,0 \\
\hline Vatairea macrocarpa (Benth.) Ducke & 83 & 0,8 & 125 & 2,0 & 125 & 0,4 & 0 & 0,0 & 0 & 0,0 \\
\hline Xylopia aromatica (Lam.) Mart. & 542 & 5,1 & 42 & 0,7 & 42 & 0,1 & 0 & 0,0 & 0 & 0,0 \\
\hline Zanthoxylum rhoifolium Lam. & 83 & 0,8 & 0 & 0,0 & 0 & 0,0 & 0 & 0,0 & 0 & 0,0 \\
\hline Zeyheria montana Mart. & 42 & 0,4 & 0 & 0,0 & 0 & 0,0 & 0 & 0,0 & 0 & 0,0 \\
\hline Total & 10.625 & 100,0 & 6.250 & 100,0 & 35.625 & 100,0 & 19.958 & 100,0 & 2.000 & 100,0 \\
\hline
\end{tabular}

Com base em outros estudos, era de se esperar que, mesmo em áreas com elevada regeneração, a introdução de novas espécies resultasse em aumento significativo da riqueza. Sampaio et al. (2007), ao introduzirem espécies por mudas e sementes em área de pastagem com elevada regeneração natural de Floresta Estacional Decidual no Brasil Central, obtiveram aumento de riqueza discreto com a introdução de sementes e aumento notável com a introdução de mudas, em comparação com a área controle (sem intervenção). De forma semelhante, Engel e Parrotta (2001), ao depositarem sementes em áreas degradadas visando à restauração de Floresta Estacional Semidecidual no sudeste do Brasil, constataram, aos 2,5 anos após a semeadura, aumento significativo da riqueza nas áreas semeadas em comparação com áreas sem intervenção. De maneira oposta, nossos resultados demonstraram que a introdução de espécies pelas técnicas de SLI, SL e PM não resultou em aumento da riqueza. A primeira explicação possível para a discrepância dos resultados é que ambos os estudos mencionados tratam de ecossistemas florestais. Além disso, as operações de manejo intrínsecas às técnicas de plantio utilizadas em nosso estudo certamente prejudicaram o potencial de regeneração natural nas parcelas destes tratamentos. $\mathrm{O}$ revolvimento do solo no Cerrado reduz drasticamente a regeneração natural de espécies nativas (Durigan et al. 1998). A roçagem mecanizada para supressão de gramíneas invasoras em áreas em restauração geralmente resulta em danos acidentais às plantas pequenas em regeneração (Sampaio et al. 2007).
Além de não resultar em aumento de riqueza, as técnicas baseadas em semeadura resultaram em alta dominância de uma única espécie. Dentre as espécies semeadas, Mabea fistulifera foi a mais bem sucedida, representando mais de $80 \%$ da densidade total das comunidades resultantes destes tratamentos. Assim, a forte dominância desta espécie resultou em baixos valores de riqueza rarefeita e, portanto, em comunidades com baixa diversidade. A dominância de uma ou poucas espécies em restauração por semeadura direta parece ser a regra, como tem sido observado em outros estudos (Engel \& Parrotta 2001, Camargo et al. 2002, Pietro-Souza \& Silva 2014). A baixa densidade relativa das outras espécies semeadas neste estudo pode ter sido ocasionada por inúmeros fatores, como a dessecação de sementes ocasionada por condições microclimáticas inadequadas (Guerin et al. 2015, Palma \& Laurance 2015), baixas taxas de germinação (Brando \& Durigan 2001, Lima et al. 2014, Ceccon et al. 2015, Palma \& Laurance 2015) e predação ou remoção de sementes (Ferreira et al. 2011, Salazar et al. 2012).

No que diz respeito à recuperação da densidade da comunidade lenhosa, a SLI foi mais eficaz do que o PM, a RNA e a RP, confirmando que a introdução dos propágulos em grande quantidade aceleraria a recuperação da estrutura da comunidade. Nas parcelas de semeadura direta foram depositadas, aproximadamente, 50 mil sementes de espécies lenhosas ( 21 sementes $\mathrm{m}^{-2}$ ou 214.067 sementes ha $\left.^{-1}\right)$. A chuva anual de sementes em vegetação de Cerrado 
varia de 410 sementes $\mathrm{m}^{-2}$ em formações mais abertas a 773 sementes $\mathrm{m}^{-2}$ em formações mais fechadas (Salazar et al. 2012). A quantidade de sementes depositadas de uma só vez nas parcelas foi,
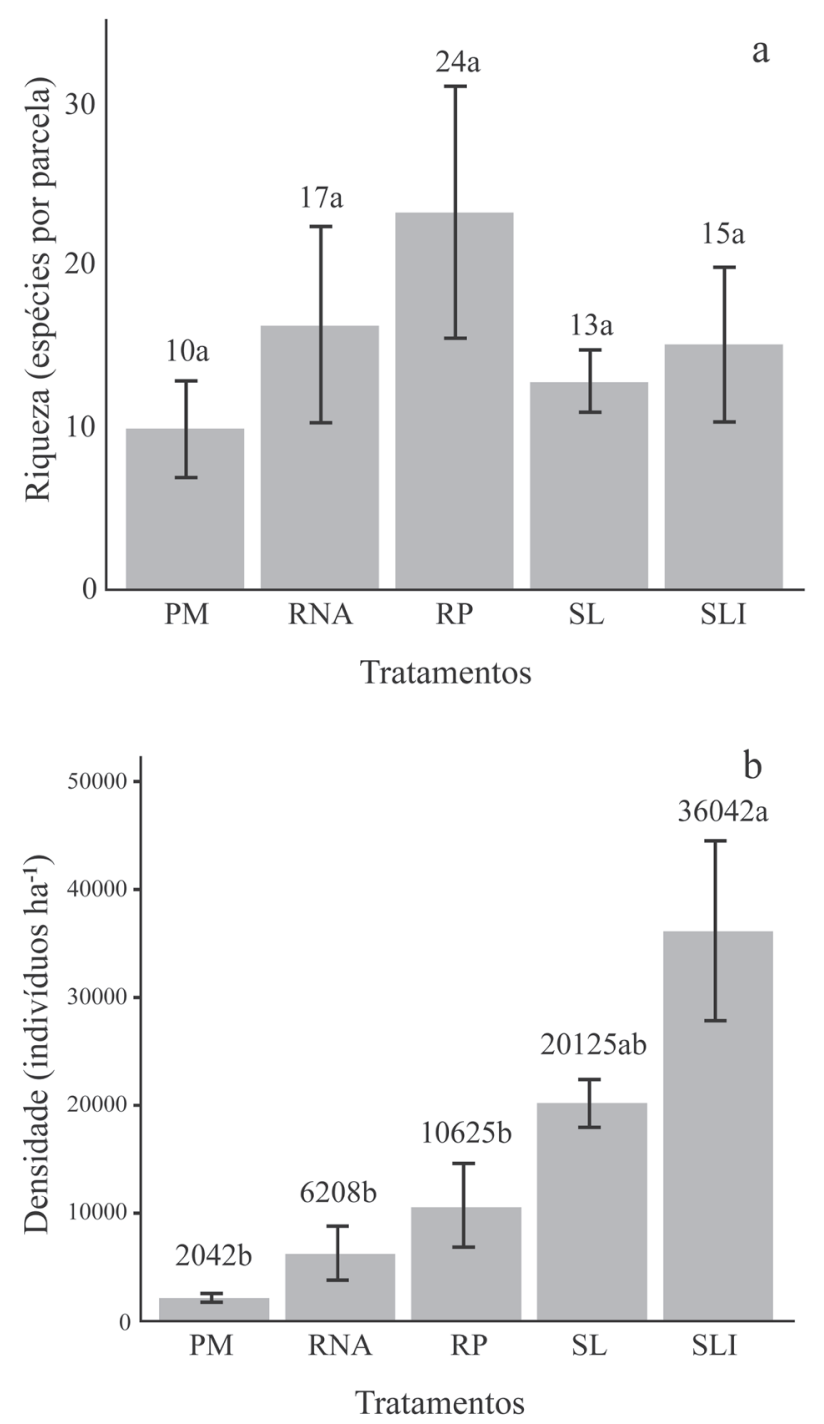

Figura 1. Valores médios de riqueza (a) e densidade (b) de espécies lenhosas por parcela nos diferentes tratamentos (técnicas de restauração). Os tratamentos foram: restauração passiva (RP), regeneração natural assistida (RNA), semeadura em linhas (SLI), semeadura a lanço (SL) e plantio de mudas (PM). Médias seguidas de letras iguais não diferem entre si a 5\% de significância pelo teste Tukey. As barras verticais ao alto de cada coluna representam o erro padrão da estimativa da análise de variância.

Figure 1. Mean values of richness (a) and density (b) of woody species per plot in the different treatments (restoration techniques). The treatments were: passive restoration (RP), assisted natural regeneration (RNA), seeding in rows (SLI), broadcast seeding (SL), and planting nursery-raised tree seedlings (PM). Means followed by the same letter do not differ at $5 \%$ significance by Tukey test. The vertical bars on top of each column represent the standard error of the estimate of the variance analysis. portanto, muito inferior à chuva natural de sementes esperada em um ano. Contudo, ao compararmos a quantidade de sementes depositadas nas parcelas de semeadura com a quantidade de mudas introduzidas nas parcelas envolvendo o plantio (854 mudas ha-1), verificamos que a introdução de sementes foi feita em densidade consideravelmente superior à introdução de mudas. Esperávamos, portanto, que ambas as técnicas de semeadura resultassem em comunidades com densidades superiores às demais técnicas. Todavia, embora isto tenha sido observado para SLI, a semeadura a lanço não diferiu dos demais tratamentos em relação à recuperação da densidade. Embora o preparo do solo, a quebra de dormência de sementes e a densidade de semeadura tenham sido iguais em SLI e SL, os equipamentos utilizados foram distintos, resultando em diferenças na profundidade em que as sementes foram enterradas no solo e na distribuição espacial das sementes nas parcelas, com exceção de Caryocar sp. e M. pubescens, que foram semeadas manualmente. A plantadora agrícola convencional utilizada para SLI parece ter favorecido o estabelecimento das espécies semeadas em comparação à semeadora-adubadora utilizada para SL. Na SLI as sementes foram enterradas homogeneamente em linhas a uma profundidade máxima de $5 \mathrm{~cm}$, enquanto na SL as sementes foram distribuídas aleatoriamente sobre o solo e enterradas posteriormente por meio de uma gradagem leve. Esta operação, provavelmente, enterrou as sementes de forma heterogênea, a profundidades inadequadas, o que pode ter resultado em menor estabelecimento de indivíduos das diferentes espécies. Doust et al. (2006), restaurando áreas degradadas nos trópicos úmidos da Austrália por meio de semeadura direta, também verificaram que a distribuição espacial das sementes e a forma como elas foram depositadas no solo exerceram influência sobre o estabelecimento das espécies, concluindo que a eficácia da semeadura direta dependerá tanto da forma de deposição das sementes quanto do potencial das espécies em se estabelecerem por meio da técnica.

Além da eficácia ecológica, avaliada com base na recuperação da riqueza e densidade da comunidade, os custos associados a cada técnica devem ser considerados no planejamento da restauração (Holl \& Aide 2011). Neste estudo, o PM apresentou o maior custo de restauração por hectare $(\mathrm{R} \$ 3.300,00)$, seguido pela SLI (R\$ 2.100,00), SL (R \$ 1.900,00), RNA (R\$ 200,00) e RP (custo zero). Ainda que a semeadura direta em linhas tenha resultado em ligeira 


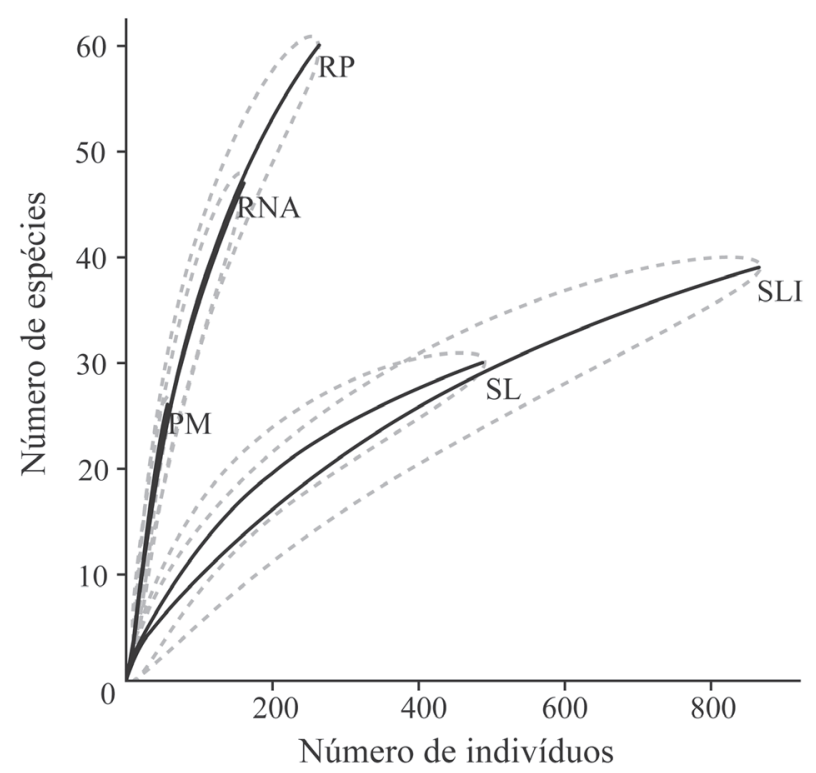

Figura 2. Curvas de rarefação construídas com base nos indivíduos de espécies lenhosas amostrados no conjunto de parcelas de cada um dos tratamentos de restauração passiva (RP), regeneração natural assistida (RNA), semeadura em linhas (SLI), semeadura a lanço (SL) e plantio de mudas (PM) em Canarana, MT, Brasil.

Figure 2. Rarefaction curves based upon all woody species individuals sampled in the set of plots of each treatment of passive restoration (RP), assisted natural regeneration (RNA), seeding in rows (SLI), broadcast seeding (SL), and planting nursery-raised tree seedlings (PM) in Canarana, Mato Grosso State, Brazil.

vantagem na rapidez de recuperação da densidade e, portanto, na rápida recobertura do terreno, os custos envolvidos na técnica são elevados em comparação com as técnicas baseadas apenas na regeneração natural, sem introdução de sementes ou mudas. Cabe a ressalva de que se a restauração tem como objetivo dirigir a composição futura do ecossistema restaurado, como seria o caso de Reserva Legal com fins de exploração econômica futura, a regeneração natural apresenta restrições, pois não permite prever as espécies que se estabelecerão. Todavia, se os custos são adotados como critério para a escolha da técnica, definitivamente a restauração ativa não seria recomendada para condições ambientais similares às da área de estudo, em que o nível de riqueza de espécies e a estrutura da vegetação foram rapidamente recuperados por regeneração natural, sem nenhuma intervenção. Portanto, com base nos resultados deste estudo não é possível apontar uma única técnica que seja recomendável para todas as situações em que se deseja restaurar a vegetação do Cerrado. A resiliência do ecossistema na área a restaurar, os custos envolvidos em cada técnica e as metas estabelecidas para o projeto de restauração (recobertura rápida do terreno para proteção ambiental, exploração econômica das espécies ou recuperação da biodiversidade) devem conduzir a diferentes decisões entre técnicas para a restauração do Cerrado.

\section{Agradecimentos}

Os autores agradecem primeiramente aos proprietários da Fazenda Angaiá, à Embrapa Agrossilvipastoril e ao Instituto Socioambiental, pela instalação e manutenção do experimento, a Júnior M. Veiga, Natalia Guerin, Renan V. Garcia, Vanderley C. Silva, Letícia Laabs, Vítor Renck, Cândida L. Mews, Gabriela Almeida pelo auxílio na coleta de dados. Agradecem ainda a Rodolfo C. R. Abreu, às editoras Maria Margarida de Melo e Natália M. Ivanauskas e aos revisores anônimos, pela contribuição para o aprimoramento do manuscrito e a e a Dora Souza Dias, pela elaboração das figuras. M.G.B.C. agradece à Coordenação deAperfeiçoamento de Pessoal de Nível Superior-CAPES pela bolsa de Mestrado, A.H.M. à Fundação de Amparo à Pesquisa do Estado de São Paulo - FAPESP pela bolsa de Doutorado e G.D. agradece ao Conselho Nacional de Desenvolvimento Científico e Tecnológico - CNPq pela bolsa de produtividade em pesquisa.

\section{Literatura citada}

Abreu, R.C.R., de Assis, G.B., Frison, S., Aguirre, A. \& Durigan, G. 2011. Can native vegetation recover after slash pine cultivation in the Brazilian Savanna? Forest Ecology and Management 262: 1452-1459.

Aronson, J. \& Alexander, S. 2013.Ecosystem restoration is now a global priority: time to roll up our sleeves. Restoration Ecology 21: 293-296.

Barros, D.P. 1966. Regeneração de espécies florestais em São Simão através da talhadia. Silvicultura em São Paulo 4: 171-178.

Bertoni, J.E.A. 1992. Reflorestamento com essências nativas e a regeneração natural do cerrado. Revista do Instituto Florestal 4: 706-709.

Bond, W.J. \& Parr, C.L. 2010. Beyond the forest edge: ecology, diversity and conservation of the grassy biomes. Biological Conservation 143: 2395-2404.

Brando, P.M. \& Durigan, G. 2001. Época de maturação dos frutos, beneficiamento e germinação de sementes de espécies lenhosas do Cerrado. Boletim do Herbário Ezechias Paulo Heringer 8: 78-90.

Brando, P.M. \& Durigan, G. 2004. Changes in cerrado vegetation after disturbance by frost (São Paulo State, Brazil). Plant Ecology 175: 205-215.

Camargo, J.L.C., Ferraz, I.D.K. \& Imakawa, A.M. 2002. Rehabilitation of degraded areas of central Amazonia using direct sowing of forest tree seeds. Restoration ecology 10: 636-644. 
Campos-Filho, E.M., da Costa, J.N., De Sousa, O.L. \& Junqueira, R.G. 2013. Mechanized direct-seeding of native forests in Xingu, Central Brazil. Journal of sustainable forestry 32: 702-727.

Ceccon, E., González, E.J. \& Martorell, C. 2015. Is Direct Seeding a Biologically Viable Strategy for Restoring Forest Ecosystems? Evidences from a Meta-analysis. Land Degradation \& Development. Disponível em http://onlinelibrary.wiley.com/doi/10.1002/ldr.2421/ abstract (acesso em 26-II-2016).

Doust, S.J., Erskine, P.D. \& Lamb, D. 2006. Direct seeding to restore rainforest species: microsite effects on the early establishment and growth of rainforest tree seedlings on degraded land in the wet tropics of Australia. Forest Ecology and Management 234: 333-343.

Durigan, G. 2003. Bases e Diretrizes para a restauração da vegetação de Cerrado. In: P.Y. Kageyama, R.E. Oliveira, L.F.D. Moraes, V.L. Engel, F.B. Gandara (orgs.). Restauração Ecológica de Ecossistemas Naturais. FEPAF, Botucatu, pp. 185-204.

Durigan, G. 2009. Estrutura e diversidade de florestas tropicais. In: S.V. Martins (org.). Ecologia de Florestas Tropicais do Brasil. Editora UFV, Viçosa, pp. 185-215.

Durigan, G., Franco, G.A.D.C., Pastore, J.A. \& Aguiar, O.T. 1997. Regeneração natural da vegetação de cerrado sob floresta de Eucalyptus citriodora. Revista do Instituto Florestal 9: 71-85.

Durigan, G., Contieri, W.A., Franco, G.A.D.C. \& Garrido, M.A.O. 1998. Indução do processo de regeneração da vegetação de cerrado em área de pastagem, Assis, SP. Acta Botanica Brasilica 12: 421-429.

Durigan, G., Contieri, W.A., Melo, A.C.G. \& Kawabata, M. 2004. Plantio de Enriquecimento em Linhas em Área de Cerradão, Assis, SP. In: O. Vilas Boas, G. Durigan, (orgs.). Pesquisas em Conservação e Recuperação Ambiental no Oeste Paulista: resultados da cooperação Brasil/Japão. Páginas \& Letras Editora e Gráfica, São Paulo, pp. 409-418.

Durigan, G., Melo, A.C.G., Max, J.C.M., Vilas Bôas, O. \& Contieri, W.A. 2011. Manual para recuperação da vegetação de cerrado. 3 ed. SMA, São Paulo.

Durigan, G., Guerin, N. \& Costa, J.N.M.N. 2013. Ecological restoration of Xingu Basin headwaters: motivations, engagement, challenges and perspectives. Philosophical Transactions of the Royal Society B: Biological Sciences. Disponível em http://dx.doi. org/10.1098/rstb.2012.0165 (acesso em 26-II-2016).

Engel, V.L. \& Parrotta, J.A. 2001.An evaluation of direct seeding for reforestation of degraded lands in central São Paulo state, Brazil. Forest Ecology and Management 152: 169-181.
Felfili, J.M., Fagg, C.W. \& Pinto, J.R.R. 2005. Modelo nativas do bioma: stepping stones na formação de corredores ecológicos pela recuperação de áreas degradadas no cerrado. In: M.B. Arruda (org.). Gestão Integrada de Ecossistemas Aplicada à Corredores Ecológicos. IBAMA, Brasília, pp. 187-209.

Ferreira, A.V., Bruna, E.M. \& Vasconcelos, H.L. 2011. Seed predators limit plant recruitment in Neotropical savannas. Oikos 120:1013-1022.

Flora do Brasil (em construção). 2020. Jardim Botânico do Rio de Janeiro. Disponível em http://floradobrasil. jbrj.gov.br/ (acesso em 26-II-2016).

Guerin, N., Isernhagen, I., Vieira, D.L.M., CamposFilho, E.M. \& Campos, R.J.B. 2015. Avanços e próximos desafios da semeadura direta para restauração ecológica. In: S.V. Martins. (org.). Restauração Ecológica de Ecossistemas Degradados. 2 ed. Editora UFV, Viçosa, pp. 331-376.

Hoekstra, J.M., Boucher, T.M., Ricketts, T.H. \& Roberts, C. 2005.Confronting a biome crisis: global disparities of habitat loss and protection. Ecology letters 8: 23-29.

Hoffmann, W.A. 1998. Post-burn reproduction of woody plants in a neotropical savanna: the relative importance of sexual and vegetative reproduction. Journal of Applied Ecology 35: 422-433.

Holl, K.D. \& Aide, T.M. 2011. When and where to actively restore ecosystems? Forest Ecology and Management 261: 1558-1563.

IBGE - Instituto Brasileiro de Geografia e Estatística. 2012. Manual Técnico da Vegetação Brasileira: sistema fitogeográfico, inventário das formações florestais e campestres, técnicas e manejo de coleções botânicas, procedimentos para mapeamentos. 2 ed. IBGE, Coordenação de Recursos Naturais e Estudos Ambientais, Rio de Janeiro.

Jørgensen, D. 2015.Ecological restoration as objective, target, and tool in international biodiversity policy. Ecology and Society. Disponível em http://www. ecologyandsociety.org/vol20/iss4/art43/ (acesso em 26-II-2016).

Kunz, S.H., Ivanauskas, N.M. \& Martins, S.V. 2009. Estrutura fitossociológica de uma área de cerradão em Canarana, Estado do Mato Grosso, Brasil. Acta Scientiarum Biological Sciences 31: 255-261.

Lehmann, C.E. 2010. Savannas need protection. Science, 327: 642-643.

Lima, Y.B.C., Durigan, G. \& Souza, F.M. 2014. Germinação de 15 espécies vegetais do cerrado sob diferentes condições de luz. Bioscience Journal 30: 1864-1872.

Magurran, A.E. 2004. Measuring biological diversity. Blackwell Science, London.

Medeiros, M.B. \& Miranda, H.S. 2008. Post-fire resprouting and mortality in cerrado woody plant species over a three-year period. Edinburgh Journal of Botany 65: 53-68. 
Melo, A.C.G., Boas, O.V. \& Nakata, H. 2004a Teste de espécies arbóreas para plantio em área de Cerrado. In: O. Vilas Boas, G. Durigan (orgs.). Pesquisas em Conservação e Recuperação Ambiental no Oeste Paulista: resultados da cooperação Brasil/ Japão. Páginas \& Letras Editora e Gráfica, São Paulo, pp. 305-314.

Melo, A.C.G., Durigan, G. \& Kawabata, M. 2004b. Crescimento e Sobrevivência de Espécies Arbóreas Plantadas em Áreas de Cerrado. In: O. Vilas Boas, G. Durigan, (orgs.). Pesquisas em Conservação e Recuperação Ambiental no Oeste Paulista: resultados da cooperação Brasil/ Japão. Páginas \& Letras Editora e Gráfica, São Paulo, pp. 447-456.

Menz, M.H.M., Dixon, K.W. \& Hobbs, R.J. 2013.Hurdles and opportunities for landscape-scale restoration. Science 339: 526-527.

Neri, A.V., Campos, E.D., Duarte, T.G., Meira Neto, J.A.A., Silva, A.D. \& Valente, G.E. 2005. Regeneração de espécies nativas lenhosas sob plantio de Eucalyptus em área de Cerrado na Floresta Nacional de Paraopeba, MG, Brasil. Acta botanica brasilica 19: 369-376.

Overbeck, G.E., Hermann, J.M., Andrade, B.O., Boldrini, I.I., Kiehl, K., Kirmer, A., Koch, C., Kollmann, J., Meyer, S.T., Müller, S.C., Nabinger, C., Pilger, G.E., Trindade, J.P.P., Vélez-Martin, E., Walker, E.A., Zimmermann D.G. \& Pillar., V.D. 2013. Restoration ecology in Brazil-time to step out of the forest. Natureza \& Conservação 11:92-95.

Palma, A.C. \& Laurance, S.G. 2015.A review of the use of direct seeding and seedling plantings in restoration: what do we know and where should we go? Applied Vegetation Science 18: 561-568.

Parr, C.L., Lehmann, C.E.R., Bond, W.J., Hoffmann, W.A. \& Andersen, A.N. 2014. Tropical grassy biomes: misunderstood, neglected, and under threat. Trends in ecology \& evolution 29: 205-213.

Pereira, S.R., Laura, V.A. \& Souza, A.L.T. $2013 \mathrm{a}$. Establishment of Fabaceae tree species in a tropical pasture: influence of seed size and weeding methods. Restoration Ecology 21: 67-74.

Pereira, S.R., Laura, V.A. \& Souza, A.L.T. 2013 b. Superação de dormência de sementes como estratégia para restauração florestal de pastagem tropical. Pesquisa Agropecuária Brasileira 48: 148-156.

Pietro-Souza, W. \& Silva, N.M. 2014 Plantio manual de muvuca de sementes no contexto da restauração ecológica de áreas de preservação permanente degradadas. Revista Brasileira de Agroecologia 9: 63-74.

Presidência da República. Lei n ${ }^{\circ}$ 12.651, de 25-V-2012. Dispõe sobre a proteção da vegetação nativa; altera as Leis ${ }^{\text {os }} 6.938$, de 31 de agosto de 1981, 9.393, de 19 de dezembro de 1996, e 11.428 , de 22 de dezembro de 2006; revoga as Leis $n^{\text {os }} 4.771$, de 15 de setembro de 1965, e 7.754, de 14 de abril de 1989, e a Medida Provisória $\mathrm{n}^{\circ} 2.166-67$, de 24 de agosto de 2001; e dá outras providências. Diário Oficial da União, Brasília, 25-V-2012. Seção I, pp. 1 - 8.
Ruiz-Jaen, M.C. \& Aide, T.M. 2005. Restoration success: how is it being measured? Restoration Ecology 13: $569-577$.

Salazar, A. \& Goldstein, G. 2014. Effects of fire on seedling diversity and plant reproduction (sexual vs. vegetative) in Neotropical savannas differing in tree density. Biotropica 46: 139-147.

Salazar, A., Goldstein, G., Franco, A.C. \& MirallesWilhelm, F. 2012. Seed limitation of woody plants in Neotropical savannas. Plant Ecology 213: 273-287.

Sampaio, A.B., Holl, K.D. \& Scariot, A. 2007. Does restoration enhance regeneration of seasonal deciduous forests in pastures in central Brazil? Restoration Ecology 15: 462-471.

Sano, S.M., Almeida, S.P. \& Ribeiro, J. F. 2008. Cerrado: ecologia e flora. v. 2. Embrapa, Brasília.

Sano, E.E., Rosa, R., Brito, J.L.S. \& Ferreira, L.G. 2010. Land cover mapping of the tropical savanna region in Brazil. Environmental monitoring and assessment 166: 113-124.

Santilli, C. \& Durigan, G. 2014. Do alien species dominate plant communities undergoing restoration? A case study in the Brazilian savanna. Scientia Forestalis 42: 371-382.

Saporetti Júnior, A.W., Meira Neto, J.A.A. \& Almado, R. 2003. Fitossociologia de sub-bosque de cerrado em talhão de Eucalyptus grandis W. Hill ex Maiden no município de Bom Despacho-MG. Revista Árvore 27: 905-910.

Scholes, R.J. \& Archer, S.R. 1997.Tree-grass interactions in savannas. Annual review of Ecology and Systematics pp. 517-544.

Silva, L.D.C.R. \& Corrêa, R.S. 2008. Sobrevivência e crescimento de seis espécies arbóreas submetidas a quatro tratamentos em área minerada no cerrado. Revista Árvore 32: 731-740.

Silva, R.R., Oliveira, D.R., da Rocha, G.P., \& Vieira, D.L.M. 2015. Direct seeding of Brazilian savanna trees: effects of plant cover and fertilization on seedling establishment and growth. Restoration Ecology 23: 393-401.

Silveira, E.R., Melo, A.C.G. \& Contiéri, W.A. 2013. Controle de gramíneas exóticas em plantio de restauração do Cerrado. In: G. Durigan, V.S. Ramos (orgs.). Manejo adaptativo: primeiras experiências na restauração de ecossistemas. Páginas \& Letras, São Paulo, pp. 5-7.

Soares-Filho, B., Rajão, R., Macedo, M., Carneiro, A., Costa, W., Coe, M., Rodrigues H. \& Alencar, A. 2014. Cracking Brazil's forest code. Science 344: 363-364.

Souza, A.P., Mota, L.L., Zamadei, T., Martin, C.C., Almeida, F.T. \& Paulino, J. 2013. Classificação climática e balanço hídrico climatológico no estado de Mato Grosso. Nativa 1: 34-43. 
Veldman, J.W., Overbeck, G.E., Negreiros, D., Mahy, G., Le Stradic, S., Fernandes, G.W., Durigan, G., Buisson, E., Putz, F.E. \& Bond, W.J. 2015a Tyranny of trees in grassy biomes. Science 347: 484-485.

Veldman, J.W., Overbeck, G.E., Negreiros, D., Mahy, G., Le Stradic, S., Fernandes, G.W., Durigan, G., Buisson, E., Putz, F.E. \& Bond, W.J. 2015b. Where Tree Planting and Forest Expansion are Bad for Biodiversity and Ecosystem Services. BioScience 65: 1011-1018.
Veldman, J.W., Buisson, E., Durigan, G., Fernandes, G.W., Le Stradic, S., Mahy, G., Negreiros, D., Overbeck, G.E., Veldman, R.G., Zaloumis, N.P., Putz, F.E. \& Bond, W.J. 2015c. Toward an old-growth concept for grasslands, savannas, and woodlands. Frontiers in Ecology and the Environment 13: 154-162.

Venturoli, F., Venturoli, S., Borges, J.D., Castro, D.S., de Melo Souza, D., Monteiro, M.M., \& Calil, F.N. 2013. Incremento de espécies arbóreas em plantio de recuperação de área degradada em solo de cerrado no Distrito Federal. Bioscience Journal 29:143-151. 